\title{
A painful dilemma? Analgesic use in sport and the role of anti-doping
}

\author{
Alan Vernec, ${ }^{1}$ Andrew Pipe, ${ }^{2}$ Andrew Slack'
}

How clinicians should address the use and abuse of analgesics in sport has been a focus of debate for many years. Concern for an athlete's health and a desire to prevent unfair distortion of performance underlie any discussion of this issue. In 1967 the original IOC list of prohibited substances specifically identified 'Narcotic Analgesics' as being prohibited in sport. The 2017 WADA Prohibited List (List) mandates that 'Narcotics' and 'Cannabinoids' are prohibited 'In-Competition'. More commonly used analgesics, including non-steroidal anti-inflammatory drugs, paracetamol, local anaesthetics, and some weak opioids such as tramadol and codeine are not prohibited. No well-defined boundary separates either the health risk or ergogenic potential of cannabinoids and narcotics versus the more commonly used analgesics.

Should more analgesics be added to the List or should narcotics and cannabis be removed? Is the use of pain medication doping? As defined by Article 2 of the World Anti-Doping Code (Code), ${ }^{1}$ doping is defined, inter alia, as the presence, use, possession or trafficking of a prohibited substance. This leads one to query: what are the key determinants for inclusion of a substance on the List? The Code criteria for the prohibition of a substance require consideration of the potential for, or enhancement of, sport performance, but also the potential for, or actual, health risk, and whether use constitutes a violation of the 'spirit of sport'-the concept of fair, ethical and respectful competition.

The List is a living document subject to continual review and modifications. Additions and deletions are made following extensive stakeholder input and expert deliberation. In considering changes, however, one must recognise the dearth of clear scientific evidence regarding the ergogenicity or health

\footnotetext{
${ }^{1}$ Department of Science and Medicine, World AntiDoping Agency (WADA), Montreal, Quebec, Canada ${ }^{2}$ Faculty of Medicine, University of Ottawa, Division of Prevention and Rehabilitation, University of Ottawa Heart Institute, Ottawa, Ontario, Canada
}

Correspondence to Dr Alan Vernec, Department of Science and Medicine, World Anti-Doping Agency (WADA), Ottawa, Ontario K1Y 4W7, Canada; alan.vernec@wada-ama.org risks associated with the use of a particular substance in specific athlete populations. The List transcends sports and borders, bringing benefits of a global harmonisation of rules, yet creating other challenges; differing medical practices, diverse cultural perspectives and sport attitudes must presently be accommodated within a single List.

Evidence suggests that the currently prohibited narcotic analgesics (opioids) and cannabinoids are not ergogenic and in fact are ergolytic. ${ }^{2}$ Both may be prescribed medically for pain management, yet both may be obtained illegally and carry potentially serious health risks, including addiction. However their health risk relative to other analgesics has never been assessed in a rigorous, scientific manner.

While no athlete should risk shortterm or long-term health consequences by carelessly returning to competition, the reality is that calculated risk-taking behaviour that dances at the edge of injury is often celebrated. In certain situations, it could be acceptable for physicians to manage their athletes' pain to allow achievement of their sporting goals. It is interesting to note that one of the most effective methods of masking pain from (localised) injury is by injection of a local anaesthetic. This intervention has resulted in fairly little controversy in the world of sports as long as the athlete has been fully apprised of the risks and the use is carefully considered.

Opioid use however remains a controversial subject: some regions of the world are gripped in epidemics of opioid abuse; others still suffer from a lack of availability of these medications for appropriate medical usage. Although low potency opiates such as codeine and tramadol are not included in the List, these medications may nevertheless occasionally be the subject of abuse. WADA monitoring of urine samples has identified elevated tramadol prevalence in certain sport settings, notably cycling. Yet most stakeholders across a wide range of sports have been quite clear in expressing the view that these medications should remain among the physician's therapeutic options. Indeed, there is a strong argument that all opioids and cannabinoids should be at the physician's disposal, but the window for using these substances in elite athletes is extremely narrow. In the rare scenario where an opioid might be contemplated because of the unique circumstances of the competition, the primary decision is whether the medication is safe, given its potential neuropsychiatric side effects that could lead to impaired decision-making or coordination. Although the Therapeutic Use Exemption process ${ }^{3}$ could allow the in-competition use of prohibited analgesics for medical reasons, the application of this rigorous process is challenging for applicants due to short-term prescribing patterns and lack of objective criteria for diagnosing pain.

There are varying and often passionate views on the role that the anti-doping mechanism should play in regulating opioids and cannabinoids. Some would suggest that the social use of drugs might better be addressed by a 'Code of Conduct' approach in which non-punitive substance abuse counselling and treatment strategies would be employed. Others argue that the use of cannabinoids and opioids is a wholly unacceptable behaviour in the sport setting and/ or potentially so dangerous that every effort should be taken to prevent their use, and thus drug testing of athletes and strict anti-doping sanctioning should continue.

The IOC Consensus Paper focuses on an approach that is grounded in the principles and best practices guiding pain management in the sport setting. The sacred trust in the athlete-physician relationship must encompass risk analysis, informed consent and the overall well-being of the patient/athlete. Any less would be to render a profound disservice to our athlete-patients-and to sport.

Acknowledgements The editorial benefited from various colleagues at different times and places, though we gratefully acknowledge the comments and suggestions of Wayne Derman, Brian Hainline and Nick Webborn.

Competing interests None declared.

Provenance and peer review Not commissioned; externally peer reviewed.

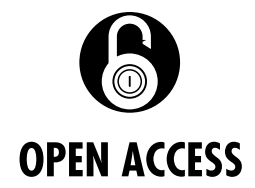

Open Access This is an Open Access article distributed in accordance with the Creative Commons Attribution Non Commercial (CC BY-NC 4.0) license, which permits others to distribute, remix, adapt, build upon this work non-commercially, and license their derivative works on 
different terms, provided the original work is properly cited and the use is non-commercial. See: http:// creativecommons.org/licenses/by-nc/4.0/

(c) Article author(s) (or their employer(s) unless otherwise stated in the text of the article) 2017. All rights reserved. No commercial use is permitted unless otherwise expressly granted.

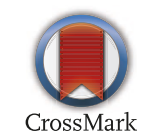

To cite Vernec A, Pipe A, Slack A. Br J Sports Med 2017;51:1243-1244.

Accepted 1 May 2017

Br J Sports Med 2017;51:1243-1244.

doi:10.1136/bjsports-2017-097867

\section{REFERENCES}

1 World Anti-Doping Agency, World Anti-Doping Code, World Anti-Doping Agency website. https://www.wada- ama.org/en/resources/the-code/world-anti-doping-code 2016, (accessed 21 Mar 2017).

2 Campos DR, Yonamine M, de Moraes Moreau RL. Marijuana as doping in sports. Sports Med 2003;33:395-9.

3 World Anti-Doping Agency, International Standard for Therapeutic Use Exemptions (ISTUE), World Anti-Doping Agency website. https://www.wada-ama.org/en/ resources/therapeutic-use-exemption-tue/internationalstandard-for-therapeutic-use-exemptions-istue 2016, (accessed 21 Mar 2017). 